\title{
A Microstrip Diplexer Using Folded Single Stepped-Impedance Resonator for 3G Microcell Stations
}

\author{
S. Theerawisitpong and P. Pinpathomrat
}

\begin{abstract}
This paper proposes a microstrip diplexer using folded single stepped-impedance resonator for $3 G$ microcell stations. The filters are designed based second-order with side coupled excitation. The measured uplink band is at 1900-1965 MHz having a passband attenuation of $1.94 \mathrm{~dB}$ and return loss of $19.5 \mathrm{~dB}$, while downlink band is at $2085-2135 \mathrm{MHz}$ having a passband attenuation of $2.20 \mathrm{~dB}$ and return loss of $22.3 \mathrm{~dB}$, where isolation between uplink and downlink band is $18.4 \mathrm{~dB}$. In addition, second harmonic is suppressed at greater than $\mathbf{4 0}$ dB upto $4700 \mathrm{MHz}$. The advantages of our diplexer include low profile, compactness, high isolation, and high selectivity.
\end{abstract}

Index Terms-Microstrip, diplexer, stepped-impedance resonator, SIR.

\section{INTRODUCTION}

Due to rapid growth of mobile internet services in Thailand, consequently, microcell stations are needed to extend capacity, especially in crowded areas, e.g. university zone, shopping malls, tourist attraction. However, interferences among $3 \mathrm{G}$ cellular networks and private WiFi networks were surprisingly discovered as surveyed in [1]. At that time, it was solved by frequency optimization, but it seemed unstable in a long term because the frequency optimized might interfere to neighbor sites. Thus, we herein propose an alternative solution using a microstrip diplexer with low profile and ease of fabrication (see Fig. 1).



Fig. 1. Remote Radio Unit (RRU) operated as a microcell station in cellular network to extend capacity in crowded areas.

In our research, we designed the second-order filters using folded single stepped-impedance resonator with side coupled

Manuscript received March 2, 2015; revised February 13, 2016. This work was supported in part by the National Research Council of Thailand under Grant 81242.

S. Theerawisitpong and P. Pinpratomrat are with the Department of Industrial Education, Faculty of Technical Education, Rajamangala University of Technology Thanyaburi, Pathum Thani, Thailand (e-mail: somboon@rmutt.ac.th, prasert@rmutt.ac.th). excitation, having compactness, high isolation, and high selectivity [2]-[6].

\section{SCHEMATIC OF RESONATOR}

The schematic of our resonator is shown in Fig. 2, where dimensions can be determined by impedance ratio $R$ and length ratio $N$. Note that ratio $R$ is defined by $Z_{1} / Z_{2}$ where $Z_{1}$ is the impedance of a strip line having a width $W_{1}$ and $Z_{2}$ is the impedance of a strip line having a width $W_{2}$, while ratio $N$ is defined by $L_{2} / L_{1}$ where $L_{1}$ is the length of a low-impedance line and $L_{2}$ is the length of a high-impedance line.
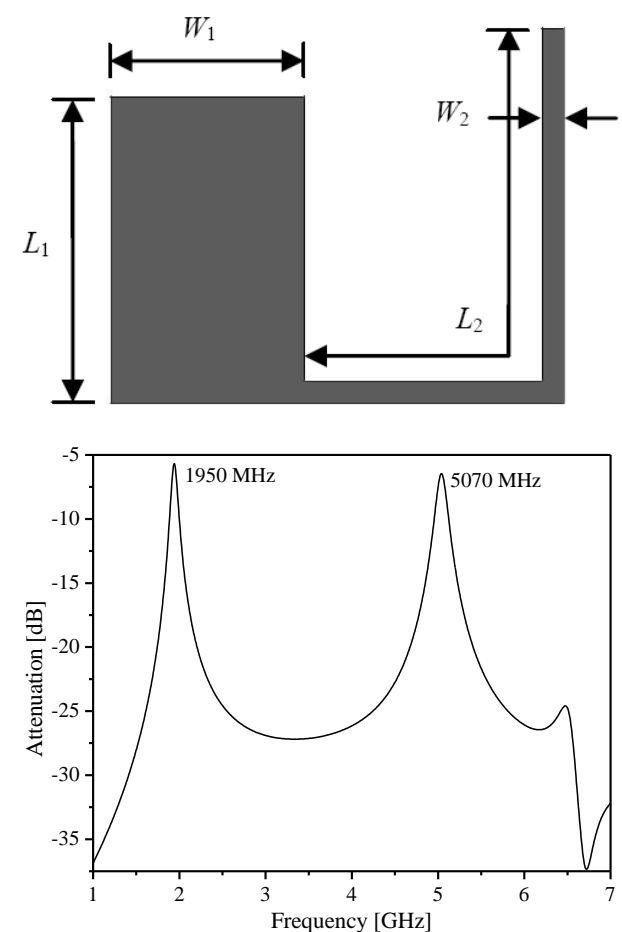

Fig. 2. Schematic of a folded single stepped-impedance resonator, and its response of resonant and second harmonic frequencies.

Regarding to off-band design as recommended in [2], ratios $R$ and $N$ were designed at 0.27 and 2, respectively, in order to achieve second harmonic suppression at more than two times of resonant frequency as shown in Fig. 2. The resonant frequency $f_{0}$ is at $1950 \mathrm{MHz}$ and second harmonic is about $2.6 f_{0}$ at $5070 \mathrm{MHz}$ which is sufficient to this work. Hence resonator dimensions are as follows: $L_{1}=14 \mathrm{~mm}, L_{2}=28.03$ $\mathrm{mm}$, for uplink band at $1920-1980 \mathrm{MHz}$, and $L_{1}=15.5 \mathrm{~mm}$, $L_{2}=30.88 \mathrm{~mm}$, for downlink band at $2110-2170 \mathrm{MHz}$, where $W_{1}=9.77 \mathrm{~mm}$ at $30 \mathrm{ohm}$ and $W_{2}=1.12 \mathrm{~mm}$ at $110 \mathrm{ohm}$. Material used is a microwave laminate \#RT/Duriod 5880 having $\varepsilon_{r}=2.2, \tan \delta=0.0009, h=1.57 \mathrm{~mm}$, and $t=0.0085$ $\mathrm{mm}$. 


\section{UPLINK AND DOWNLINK FILTERS DESIGN}

\section{A. Excitation Ports}

Our diplexer was designed based the second-order filters with side coupled excitation as shown in Fig. 3. In the figure, port 1 is the input/output port of uplink and downlink streams using a 50-ohm line at a width of $4.84 \mathrm{~mm}$ having a length of $37.2 \mathrm{~mm}$, while port 2 is an output of uplink stream and port 3 is an input of downlink stream. Regarding to impedance matching to keep a low return loss, ports 2 and 3 were designed as a shaper line including a 50-ohm line at a width of $4.84 \mathrm{~mm}$ having a length of $18.5 \mathrm{~mm}$, and a 35 -ohm line at a width of $7.84 \mathrm{~mm}$ having a length of $14.4 \mathrm{~mm}$.

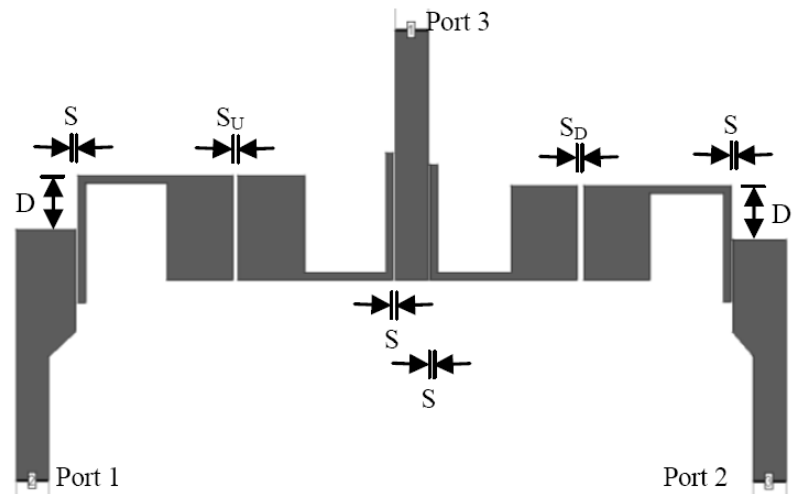

Fig. 3. Schematic of proposed diplexer including uplink and downlink filters based the second-order filter with side coupled excitation.

\section{B. Passband Design}

Referring to filter design in [2], [7], the pass-bandwidth of uplink filter at $1920-1980 \mathrm{MHz}$ was determined by a space $S_{U}$ of $0.8 \mathrm{~mm}$ and a port position $D$ of $8 \mathrm{~mm}$. On the other hand, pass-bandwidth of downlink filter at $2110-2170 \mathrm{MHz}$ was determined by a space $S_{D}$ of $0.94 \mathrm{~mm}$ and a port position $D$ of $8 \mathrm{~mm}$. In addition, the space between port and resonator $S$ was designed at a small distance of $0.3 \mathrm{~mm}$ to keep strong mixed coupling excitation. The result of our design was verified by a 3D full-wave electromagnetic simulator, as shown in Fig. 4.

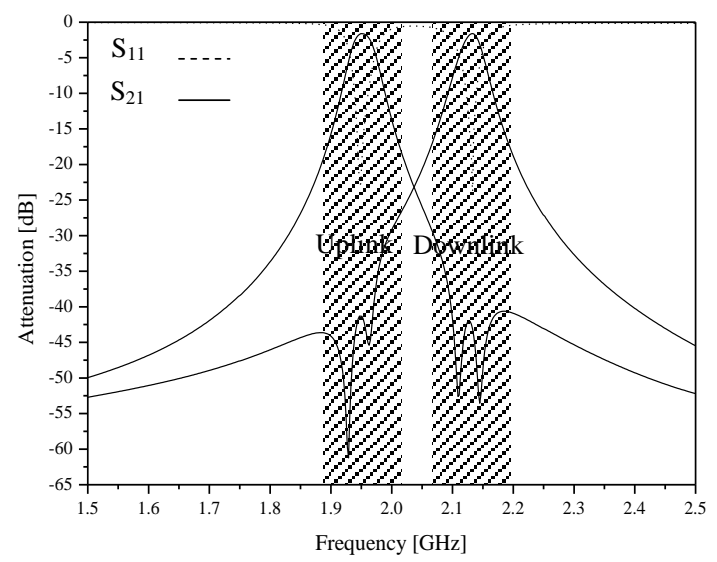

Fig. 4. The passband responses of uplink and downlink filters calculated by a 3D full-wave electromagnetic simulator.

In Fig. 4, filter performance was represented by insertion loss $S_{21}$ denoted by the bold line and return loss $S_{11}$ denoted by the dotted line. At uplink band, frequency range is at 1920-1980 MHz having a passband attenuation of $1.598 \mathrm{~dB}$ and a return loss of $18.59 \mathrm{~dB}$. At downlink band, frequency range is at $2110-2170 \mathrm{MHz}$ having a passband attenuation of $1.61 \mathrm{~dB}$ and a return loss of $23.88 \mathrm{~dB}$. Meanwhile the isolation between uplink and downlink band is $23.25 \mathrm{~dB}$.

\section{Off-Band Design}

In the design, second harmonic was designed at 2.6 times of resonant frequency using stepped-impedance technology at ratios $R$ at 0.27 and $N$ at 2 . Thus second harmonic frequencies of uplink and downlink filters were designed at $5070 \mathrm{MHz}$ and $5460 \mathrm{MHz}$, respectively, as shown in Fig. 5. In the figure, uplink filter performance is denoted by the bold line and downlink filter performance is denoted by the dotted line. In particular, suppression band was obtained with a noise margin at greater than $45 \mathrm{~dB}$.

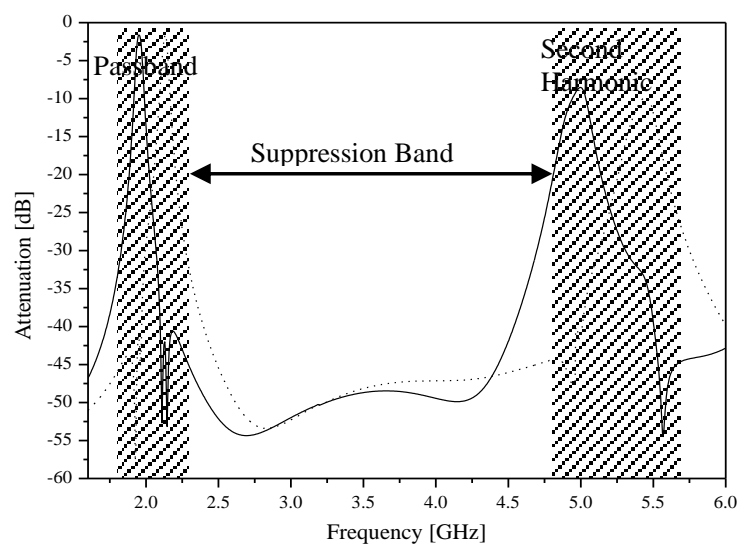

Fig. 5. The calculated result of uplink and downlink filters performance showing passband and second harmonic frequencies.

\section{Matching Condition}

The dimensions of ports 2 and 3 were optimized to achieve a low return loss regarding to matching condition, while port 1 was designed as a 50-ohm line to avoid complicated structure for uplink and downlink streams through the same path. The optimization approaches of ports 2 and 3 are demonstrated in Fig. 6(a) and Fig. 6(b). Considering optimization results in the figure, port position $\mathrm{D}$ at $8 \mathrm{~mm}$ offers a return loss at $27.5 \mathrm{~dB}$ and shaper size at $6.84 \mathrm{~mm}$ offers a return loss at $43.5 \mathrm{~dB}$ but the pass-bandwidth may be varied. Therefore, optimized port position and shaper size were recommended at $8 \mathrm{~mm}$ and 7.84 $\mathrm{mm}$, respectively, in order to keep a pass-bandwidth at 60 $\mathrm{MHz}$ as designed.

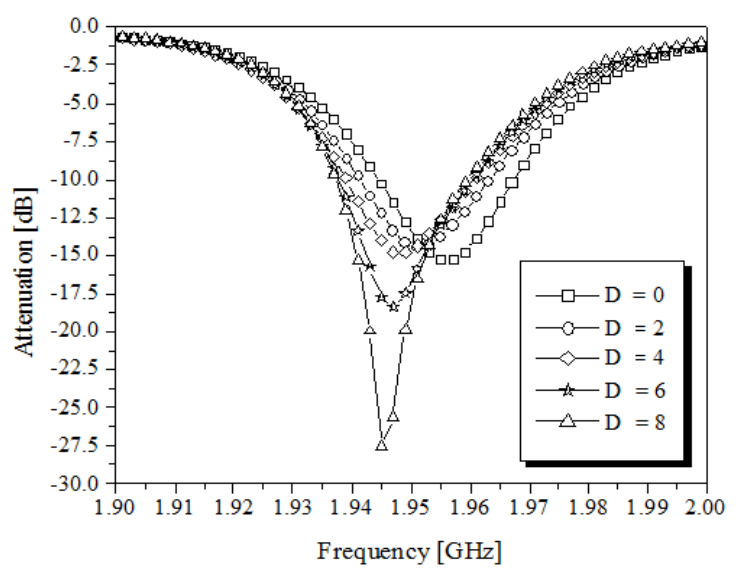

(a) 




(b)

Fig. 6. The optimization results of (a) port position D and (b) shaper size, to meet a matching condition.

\section{DiPLEXER PROTOTYPE}

The prototype fabricated with lithography technology is shown in Fig. 7. However, actual dimensions are different from calculation due to fabrication constraints, as shown in Table I, thus the calculated result is slightly different from the measured results as described in the next section.



Fig. 7. The diplexer prototype based second-order filters using folded single stepped-impedance resonator with side-coupled excitation.

TABLE I: COMPARISON OF DESIGN VS. ACTUAL DIMENSIONS

\begin{tabular}{|c|c|c|c|}
\hline \multirow{4}{*}{} & Dimensions [mm] & Design & Actual \\
\hline \multirow{4}{*}{ UL Filter } & $L_{1}$ & 15.5 & 15.0 \\
\cline { 2 - 4 } & $L_{2}$ & 30.88 & 30.5 \\
\cline { 2 - 4 } & $W_{1}$ & 9.77 & 8.278 \\
\cline { 2 - 4 } & $W_{2}$ & 1.12 & 0.875 \\
\cline { 2 - 4 } & $S_{\text {port 1-resonator }}$ & 0.3 & 0.507 \\
\cline { 2 - 4 } & $S_{\text {port 3-resonator }}$ & 0.3 & 0.564 \\
\cline { 2 - 4 } & $S_{U}$ & 0.8 & 1.021 \\
\cline { 2 - 4 } & $D$ & 8.0 & 6.985 \\
\hline \multirow{5}{*}{ DL Filter } & $L_{1}$ & 14.0 & 13.5 \\
\cline { 2 - 4 } & $L_{2}$ & 28.03 & 27.75 \\
\cline { 2 - 4 } & $W_{1}$ & 9.77 & 8.25 \\
\cline { 2 - 4 } & $W_{2}$ & 1.12 & 0.885 \\
\cline { 2 - 4 } & $S_{\text {port 2-resonator }}$ & 0.3 & 0.55 \\
\cline { 2 - 4 } & $S_{\text {port 3-resonator }}$ & 0.3 & 0.502 \\
\cline { 2 - 4 } & $S_{D}$ & 0.94 & 1.171 \\
\cline { 2 - 4 } & $D$ & 8.0 & 6.892 \\
\hline
\end{tabular}

\section{MEASUREMENT RESUltS}

The proposed filters performances measured by a vector network anaylyzer are shown in Fig. 8 and Fig. 9. In Fig. 8, uplink and downlink filters performance was verified as the following results. At uplink band, passband frequency is at $1900-1965 \mathrm{MHz}$ with passband attenuation at $1.94 \mathrm{~dB}$ and return loss at $19.5 \mathrm{~dB}$. At downlink band, passband frequency is at $2085-2135 \mathrm{MHz}$ with passband attenuation at $2.2 \mathrm{~dB}$ and return loss at $22.3 \mathrm{~dB}$. The isolation between uplink and downlink band is $18.4 \mathrm{~dB}$. However, a small loss at 1800 $\mathrm{MHz}$ was occurred, due to mobile signals interference during our measurement.

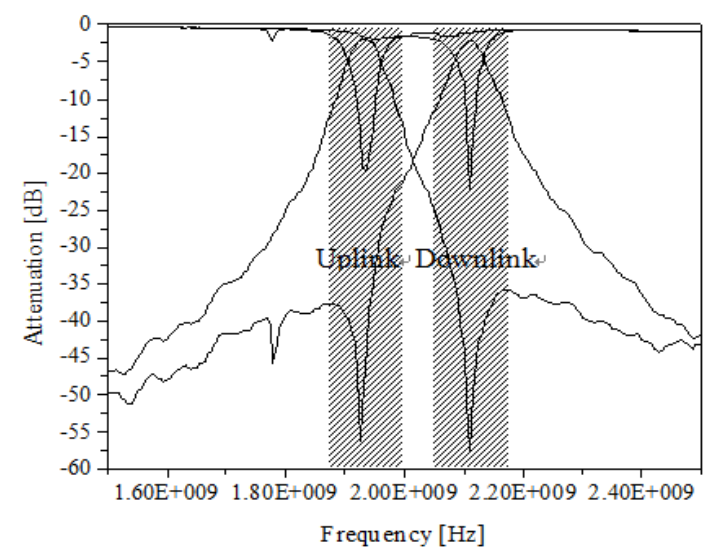

Fig. 8. The measured results of diplexer prototype at uplink and downlink bands represented by insertion and return losses.

In the meantime, second harmonic suppression was also verified as shown in Fig. 9. In the figure, second harmonics of uplink and downlink filters were suppressed at $5032 \mathrm{MHz}$ and $5460 \mathrm{MHz}$, respectively, where suppression band was achieved with a high noise margin at greater than $40 \mathrm{~dB}$ up to $4700 \mathrm{MHz}$. By the way, the comparison of calculated and measured results is summarized as shown in Table II, with respect to engineer's suggestions aimed to employ for the $3 \mathrm{G}$ microcell stations as follows: passband attenuation at less than $2.5 \mathrm{~dB}$, return loss at less than $20 \mathrm{~dB}$, isolation at less than $15 \mathrm{~dB}$, and second harmonic at more than 2 times of passband.

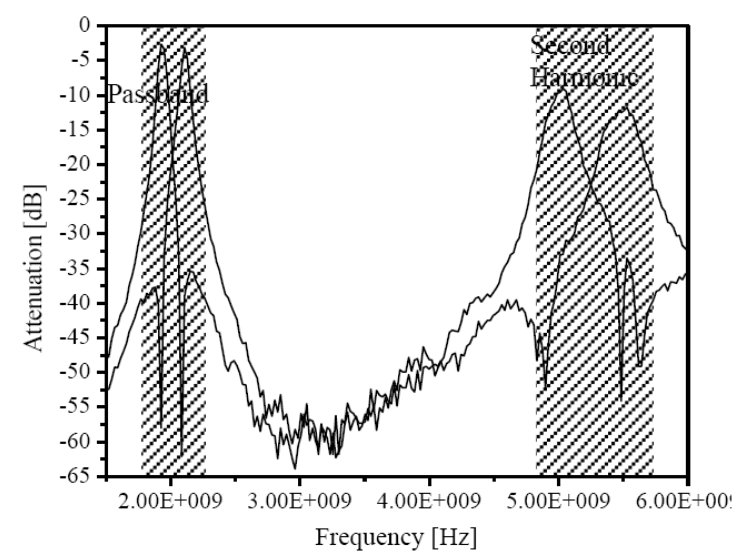

Fig. 9. The measured result of diplexer prototype on a wide band view to verify second harmonic suppression performance.

The specifications exhibited in the table below showed that our diplexer performance was acceptable with respect to the requirement.

TABLE II: COMPARISON OF CALCULATED VS. MEASURED RESUlTS

\begin{tabular}{|l|c|l|c|}
\cline { 2 - 4 } \multicolumn{1}{c|}{} & Requirement & Calculation & Measurement \\
\hline Uplink band $[\mathrm{MHz}]$ & \multicolumn{2}{|c|}{$1920-1980$} & $1900-1965$ \\
\hline $\begin{array}{l}\text { Downlink band } \\
{[\mathrm{MHz}]}\end{array}$ & \multicolumn{2}{|c|}{$2110-2170$} & $2085-2135$ \\
\hline Passband atten. & $\leq 2.5$ & & \\
\hline
\end{tabular}




\begin{tabular}{|l|c|c|c|}
\hline $\begin{array}{l}\text { [dB] } \\
\text { - Uplink band } \\
\text { - Downlink band }\end{array}$ & & $\begin{array}{l}1.598 \\
1.610\end{array}$ & $\begin{array}{l}1.94 \\
2.20\end{array}$ \\
\hline $\begin{array}{l}\text { Return loss [dB] } \\
\text { - Uplink band } \\
\text { - Downlink band }\end{array}$ & $\geq 20$ & 18.59 & 19.5 \\
\hline Isolation [dB] & $\geq 15$ & 22.88 & 22.3 \\
\hline $\begin{array}{l}\text { Second harmonic } \\
\text { suppression }\end{array}$ & $>2 f_{0}$ & \multicolumn{3}{|c|}{$2.6 f_{0}$} \\
\hline
\end{tabular}

\section{CONCLUSIONS}

In this paper, a microstrip diplexer based second-order filters using folded single stepped-impedance resonator with side-coupled excitation has been proposed with the advantages including low profile, compactness, high isolation, and high selectivity. The low profile and compactness were obtained by second-order filters using our resonator. Besides, the high isolation between uplink and downlink bands may be affected by side coupled excitation offering a transmission zero for each passband. Finally, the second harmonic suppression at $2.6 f_{0}$ with a noise margin at greater than $40 \mathrm{~dB}$ upto $4700 \mathrm{MHz}$ was achieved by stepped- impedance technology as described in the off-band design. Moreover, high return loss regarding to matching condition was optimized using shaper ports.

The proposed diplexer performance was acceptable as well However, uplink and downlink passbands should be tuned as similar to ITU's recommendations, which will be studied in the future.

\section{ACKNOWLEDGMENT}

The authors would like to gratefully thank the National Research Council of Thailand for supporting the research grant, Rajamangala University of Technology Thanyaburi for funding under the Enterprises-University Cooperation Project, and Mr.Direk Homchuen for cellular network survey and suggestions.

\section{REFERENCES}

[1] S. Theerawisitpong, D. Homchuen, and P. Pinpathomrat, "The study and analysis on air-interface problems over GSM cellular network in
Central Pattaya area,” Procedia Engineering, vol. 32, pp. 336-341, Nov. 2011.

[2] S. Theerawisitpong, T. Suzuki, N. Morita, and Y. Utsumi, "Design of microstrip bandpass filters using SIR with even-mode harmonics suppression for cellular system," IEICE Trans. Elect., vol. 93-C, pp. 867-876, Jun. 2010.

[3] B. Strassner and K. Chang, "Wide-band low-loss high-isolation microstrip periodic-stub diplexer for multiple-frequency applications," IEEE Trans. Microw. Theory \& Tech., vol. 49, pp. 1818-1820, Oct. 2001.

[4] T. Yang, P.-L. Chi, and T. Itoh, "High isolation and compact diplexer using the hybrid resonators," IEEE Microw. Wirel. Comp. Lett., vol. 20, pp. 551-553, Oct. 2010.

[5] H. W. Deng, Y. J. Zhao, F. Fu, X. J. Zhou, and Y. Y. Liu, "Compact and high isolation microstrip diplexer for GPS and UWB applications," IEEE Elect. Lett., vol. 49, pp. 659-651, Jun. 2013.

[6] N. A. Wahab, M. K. M. Salleh, O. H. Hassan, and Z. Awang, "Side-coupled single-mode ring resonator with transmission zeros," in Proc. IEEE Symp. Ind. Elect. \& Apps., pp. 590-592, Sept. 2011.

[7] G. Matthaei, L. Young, and E. M. T. Jones, Microwave Filters, Impedance-Matching Networks, and Coupling Structures, North Bergan, NJ: Artech House Inc., 1985.

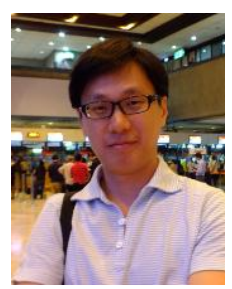

S. Theerawisitpong was born on June 29, 1975 in Samutprakan, Thailand. He received the B.S. degree in 1997 from King Mongkut's Institute of Technology Thonburi, the M.E. degree in 2005 from King Mongkut's Institute of Technology North Bangkok, and the D.E. degree in 2010 from Nippon Institute of Technology, Japan, all in electrical engineering.

$\mathrm{He}$ is now working at the High-Frequency Innovation and Applications Laboratory, Department of Industrial Education, Faculty of Technical Education, Rajamangala University of Technology Thanyaburi, Pathum Thani, Thailand, as an assistant professor. His research interests include microwave filter \& antenna, non-destructive testing with high frequency bands, and electromagnetic applications.

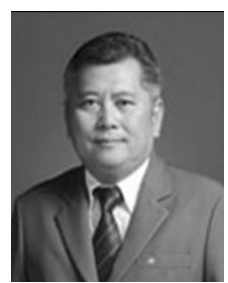

P. Pinpathomrat was born on November 21, 1961, in Nakhon Pathom, Thailand. $\mathrm{He}$ received the B.Tech.Ed. degree in electrical engineering from Rajamangala Insitute of Technology, Southern Campus, the M.E. degree in electrical engineering from Prince of Songkla University, and the Ph.D. degree in public administration from University of Northern Philippines, in 1985, 1996, and 2008, respectively.

He is now working at the Division of Electrical Education, Department of Industrial Education, Faculty of Technical Education, Rajamangala University of Technology Thanyaburi, as an associate professor. His research interests include electrical power system, automation control, and industrial management. 